\title{
RETRACTED ARTICLE: Vocational education reform based on improved convolutional neural network and speech recognition
}

\section{Rui Yang ${ }^{1}$}

Received: 11 June 2021 / Accepted: 29 July 2021 / Published online: 11 August 2021

(C) The Author(s), under exclusive licence to Springer-Verlag London Ltd., part of Springer Nature 2021

The Editor-in-Chief and the Publisher have retracted this article because the content of this article is nonsensical. The peer review process was not carried out in accordance with the Publisher's peer review policy. The author has not responded to correspondence regarding this retraction. The online version of this article contains the full text of the retracted article as Supplementary Information.

Supplementary Information The online version contains supplementary material available at https://doi.org/10.1007/s00779-021-01614-4.

Rui Yang

jianpan4321@126.com

1 Chongqing City Management College, Chongqing 401331, China 